Article

\title{
The Importance of the "Local” in Walkability
}

\section{Cynthia Carlson ${ }^{1, *}$, Semra Aytur ${ }^{2}$, Kevin Gardner ${ }^{3}$ and Shannon Rogers ${ }^{4}$}

1 Civil Engineering Department, Merrimack College, 315 Turnpike Street, North Andover, MA 01845, USA

2 Department of Health Management and Policy, University of New Hampshire, Hewitt Hall, 4 Library Way, Durham, NH 03824, USA; E-Mail: semra.aytur@unh.edu

3 Civil Engineering, Natural Resources and Earth Systems Science Program, Department of Civil and Environmental Engineering, University of New Hampshire, Gregg Hall, 33 Colovos Road, Durham, NH 03824, USA; E-Mail: kevin.gardner@unh.edu

4 Center for the Environment, Plymouth State University, 17 High Street, Plymouth, NH 03824, USA; E-Mail: shrogers@mail.plymouth.edu

* Author to whom correspondence should be addressed; E-Mail: carlsonc@merrimack.edu; Tel.: +1-978-837-5395.

Academic Editor: Derek Clements-Croome

Received: 16 June 2015 / Accepted: 16 October 2015 / Published: 22 October 2015

\begin{abstract}
Transportation infrastructure and transportation behaviors consume significant natural resources and are costly to municipalities, states, and the federal government. Small cities, in particular, may find themselves with high costs. Although transportation has been extensively investigated, methods that may enable small cities to act are still lacking. To investigate the influence that neighborhood-level built environment characteristics have on adult personal transportation decisions within small cities, this study combined community-based research, a multi-level analysis of residents, and a case study approach in two (North-Eastern United States) New Hampshire cities, Portsmouth and Manchester. Neighborhood-level physical characteristics were determined using Geographic Information Systems and visual surveys. Resident-level characteristics and behaviors were determined by survey of adult residents. Data were supplemented with input from and collaboration with city representatives. The results showed significant relationships between self-reported destination walking and built environment characteristics in the neighborhoods studied. Furthermore, the results showed variability between neighborhoods, underscoring the importance of local factors and behaviors. The results suggested that small cities and
\end{abstract}


their regional planning organizations can make changes to specific existing neighborhoods to remove barriers to walking and allow more residents to choose walking as a transportation mode, but the changes that are most effective vary by neighborhood.

Keywords: built environment; walkability; physical activity; multi-level analysis; small cities

\section{Introduction}

The question of whether the built environment is associated with transportation behavior and physical activity has been explored from many different disciplinary perspectives, including transportation [1], health [2,3], planning [4,5], and climate change [6]. Some studies largely focus on urban form and neighborhood design (e.g., traditional, suburban, sprawl, inner/outer ring) [7-10], while other studies examine specific measurable correlates of the built environment to transportation behavior [11-15] or what barriers, perceived or physical, might exist to walking in neighborhoods. Studies also note the paucity of research on the specific built environment metrics that are related to transportation decisions and the nature of those relationships [16,17], particularly in smaller cities.

Urban centers are not homogeneous entities [18], structural differences abound, further compounded by social, cultural, and environmental factors. While we instinctively understand that Boston and Albuquerque will have different transportation drivers, research and best practices are often perceived as too non-specific to meaningfully inform local policy decisions. The majority of U.S. cities are not making much progress towards improving walkability, even though the economic and health benefits have been established [19,20], and both millennials and empty nesters identify a preference for walkability [21]. One factor standing in the way of developing a method for cities to increase walkability, is the focus on large cities and averages across locations, and therefore on one-size-fits-all categorization of problems and of solutions. This may not adequately bridge the gap between engineering and sociology in local contexts. There may not be a way to simply "solve" the problem with improved infrastructure. True solutions require understanding that individual residents, individual neighborhoods, individual cities and regions all have individual drivers which may vary with size of the urban center [22,23]. To implement improvements, a context-specific approach must be taken. Studies from other fields have found significant differences between small and large cities [24], however transportation differences between large and small cities and the neighborhoods within them have not been studied. Certainly, neighborhood residents and local and regional authorities must not only be consulted, but must be actively engaged in both the identification of any "problems" and subsequent "solutions". However, how might this process look for smaller cities?

Small cities, and therefore small municipal governments, vastly outnumber larger cities, with $86 \%$ of United States' urban areas representing populations of less than 50,000, and $92 \%$ of urban areas having populations of less than 100,000 [25]. Even so, the largest cities, such as San Francisco, Seattle, and Washington, DC, are more often the focus of studies on walking [8]. Thus, authorities in small to medium-sized cities wishing to redesign or retrofit existing neighborhoods to be more "walkable" have general guidelines (such as new urbanism [26] or Leadership in Energy \& Environmental Design (LEED) Neighborhood Standards [27]), but may still struggle with which guidelines are most relevant 
for their communities and budgets, and with how to implement these locally within existing built environments for the best results [28-30].

Although some are suburbs of or adjacent to larger cities and therefore themselves dependent upon larger cities for services, some smaller cities and their governments have unique challenges and needs associated with transportation and the built environment. These may include providing services and maintaining infrastructure for a more dispersed population (transportation, drinking/waste water, etc.), providing support services (schools, hospitals, jobs, etc.) for surrounding rural communities, and leveraging funding for operating costs of these services [31], emphasizing the need to include regional planning when considering changes to local infrastructure for sustainability. In addition, small cities and their governments may experience differences in health and health care, including fewer health care visits by residents [32] and higher obesity rates [33]. These differences underscore the importance of investigating transportation decisions in smaller cities and their implications for both local and regional planning.

If the built environment were altered to increase physical activity and to reduce automotive vehicle miles traveled [34], co-benefits of reducing energy use and greenhouse gas emissions would arise [35,36]. Pitkin and Myers [37] point out that as baby boomers age it would be wise to plan for "smart reuse" of existing land uses, including improved efficiency of built environment design for reduced need to drive. Changes might be easier during periods of growth, when change in local infrastructure is likely to be occurring anyway, as well as during periods of decline, when such alterations might increase marketability or usability of existing land uses and patterns. Even if the built environment were altered to allow those with a preference for increased physical activity to act on their preferences, allowing those who "self-select" for more walkable neighborhoods to have that option may still increase walkability [38,39]. In any case, specifics of local form, needs, and culture need to be considered [40].

To investigate how the local built environment impacts personal transportation decisions, it is necessary to collect data at the local scale. Although the regional scale is important, in particular to population-level transportation characteristics [41] and geographic health disparities [42], built environment characteristics that are most easily changed/retrofitted and are therefore of interest here are often averaged to represent the overall form of the city. Thus, potentially important differences in structure might be overlooked during research at larger scales [43,44]. While larger, regional scale will be of interest in investigating overall transportation patterns and population level dynamics and may even indirectly influence more local environments, if we are investigating which built environment characteristics are most important in making a specific locale more "walkable", the neighborhood scale appears to be an appropriate place to start [45]. Comparing resident behavior between neighborhoods of different design may best elucidate how those designs relate to personal transportation behavior, and provide manageable retrofit projects for municipalities.

As walking for transportation versus recreation has been shown to have different correlates [46,47], we are specifically interested in studying walking as a mode of transportation behavior, rather than recreational walking. The goal of this paper is to measure the influence that several specific built environment characteristics have upon "destination" or "utilitarian" walking of adults living in small cities, and to estimate the variability in local transportation behavior that is correlated with adult physical environment in the studied neighborhoods. We then use these metrics to illustrate how changes in 
the built environment might improve local sustainability in smaller cities by removing physical or perceived barriers to destination walking.

\section{Methods}

\subsection{Case Studies: Selection of Cities and Neighborhoods}

Selecting case studies from within New Hampshire removes certain confounders that could arise from the selection of communities from different states, including variation in state regulations and differences in climate, culture, and seasons. In alignment with Community-Based Participatory Research (CBPR) principles [48], it was important to work collaboratively with our case study municipalities; we hoped our work would be relevant and useful to those municipalities, as research they themselves helped to design. To achieve this goal, municipal employees were central at several focus groups and individual meetings through the study period, providing input on survey design, neighborhood selection, and desired deliverables. The overall study framework was similar to the CBPR framework described by Leung et al. [48], including communication, input, and feedback with community and municipal leaders at all stages of the project.

\subsubsection{Portsmouth}

Portsmouth, New Hampshire, a small city on New Hampshire's seacoast, is fostering walkability and sustainability. Portsmouth was the Northeast's first designated eco-municipality [49], agreeing to include principles of sustainability in city master planning. In early 2008, the city appointed a sustainability coordinator [50] to oversee sustainability initiatives in city departments. Since that time, the city has installed an energy saving roof on City Hall, replaced lighting fixtures in a parking garage, and purchased a "zero-gas" electric truck for parking enforcement. The city has also engaged in public awareness campaigns, such as a Sustainability Fair and an energy challenge with the City of Keene. Residents have formed study circles around The Natural Step [51] educating themselves and each other about ways the community can improve its own sustainability.

With 21,440 residents in 2013 (calculated through Google public data using United States Census data [25]), the city has a downtown area that is vibrant and attractive to both natives and tourists. Portsmouth is a small, relatively wealthy city that has taken steps towards sustainability and is ready to investigate what might be the most effective next steps.

\subsubsection{Manchester}

Manchester is New Hampshire's largest city, with 110,378 residents in 2013 (calculated through Google public data using United States Census data [25]). Manchester has an urban core and suburban or rural outskirt. Surrounded by smaller towns and rural areas that largely depend upon the health and social support infrastructure in Manchester, regional planning and management is a central issue in municipal service planning. The municipal planning and health departments staff is active and engaged, and while there is no staff specifically tasked with implementing sustainability projects, as in Portsmouth, public health is a unifying issue that is carried across several departments in Manchester. 
Manchester has a relatively large refugee and international population, with over 76 different languages spoken in the public schools [52]. Cultural differences within and between neighborhoods may influence the acceptability of walking, associating with neighbors, allowing children to play outdoors alone, and other factors that potentially influence physical activity and public health.

Manchester is a small city struggling to develop ways to improve the public health and social capital of residents without funds to drastically change the existing built environment. It offers the opportunity to study what cities might think about first, i.e., the "low hanging fruit" issues around which cities might rally residents, or simple changes that cities could make to reduce barriers to walking. The City's health needs assessment [53] and Neighborhood Health Improvement Strategy [54] acknowledge transportation, recreation, and the physical environment among elements of community design that impact health and quality of life.

\subsubsection{Comparing the Case Studies}

Both of the municipalities have distinct historic neighborhoods, defined by the city itself and/or by the residents. These manageable pieces allowed researchers to investigate how the built environment at the neighborhood scale is associated with personal transportation decisions. More rural towns, with less distinct neighborhoods, would be more difficult to study in this way, lacking the variety of development styles found in both Portsmouth and Manchester. Both cities have a variety of development types, including downtowns, neighborhoods that are satellite to downtown, and more "sprawl"-type development, characterized by low-density, segregated land-use, and lack of "activity centers" [41]. This variety allowed us to approach residents of areas that are representative of different forms of built environment. Finally, focusing the study on specific neighborhoods helped to manage the physical process of distributing surveys.

\subsubsection{Selecting the Neighborhoods}

Initially, ten neighborhoods were selected in each city. Several smaller areas were added to increase the variety of development types studied and to oversample for the lower income brackets for increased representation of disadvantaged residents [12]. However, these additional areas were not large enough for 100 residents to be surveyed. Overall, with input from municipal representatives, 22 neighborhoods were selected to offer a range of built-environment/development styles and socio-economic statuses, while also being of similar size and geometry. Selected demographics and transportation behaviors (collected by survey) of respondents in the neighborhoods are included in Tables 1 and 2. 
Table 1. Census and sample demographics.

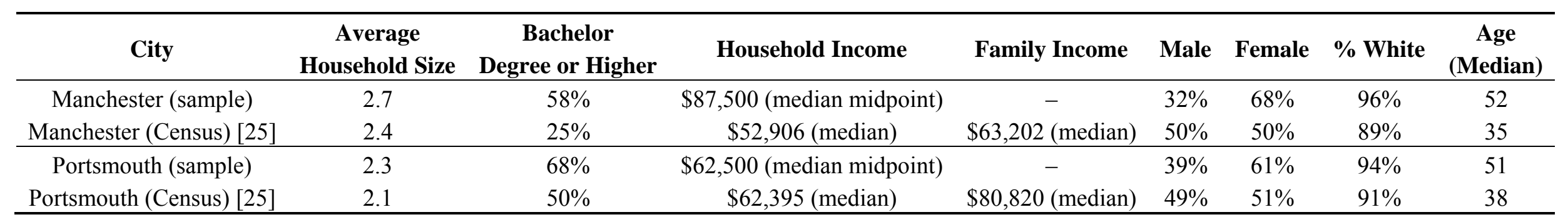

Table 2. Descriptive statistics of selected neighborhood socio-demographics and transportation behaviors.

\begin{tabular}{|c|c|c|c|c|c|c|c|c|}
\hline $\begin{array}{l}\text { Neighborhood } \\
\text { Name }\end{array}$ & Code & $\begin{array}{c}\text { \% Response } \\
\text { Rate }\end{array}$ & $\begin{array}{l}\text { Average } \\
\text { Income }\end{array}$ & Ave Age & $\begin{array}{l}\text { \% Residents Walk at } \\
\text { Least Once a Week }\end{array}$ & $\begin{array}{c}\text { \% Residents Listing } \\
\text { Sidewalk as Barrier * }\end{array}$ & $\begin{array}{c}\text { Ave Num Places } \\
\text { Do Walk ** }\end{array}$ & $\begin{array}{c}\text { Ave Num Places } \\
\text { Can Walk }\end{array}$ \\
\hline Manch Average & - & $31 \%$ & $\$ 89,000$ & 52 & $55 \%$ & $50 \%$ & 2.7 & 5.2 \\
\hline Bodwell & B & $31 \%$ & $\$ 104,000$ & 42 & $65 \%$ & $55 \%$ & 0.3 & 1.5 \\
\hline West Granite & G & $24 \%$ & $\$ 42,000$ & 54 & $63 \%$ & $54 \%$ & 3.5 & 6.6 \\
\hline Colonial/Pickering & $\mathrm{J}$ & $15 \%$ & $\$ 46,000$ & 41 & $22 \%$ & $33 \%$ & 1.7 & 2.9 \\
\hline MacCauley/Smyth & M & $42 \%$ & $\$ 100,000$ & 58 & $52 \%$ & $43 \%$ & 3.0 & 6.5 \\
\hline North End & $\mathrm{N}$ & $40 \%$ & $\$ 132,000$ & 54 & $68 \%$ & $63 \%$ & 3.6 & 7.0 \\
\hline Southside/St Anth. & $\mathrm{P}$ & $45 \%$ & $\$ 74,000$ & 54 & $42 \%$ & $44 \%$ & 2.5 & 6.8 \\
\hline Corey Square & Q & $20 \%$ & $\$ 45,000$ & 50 & $60 \%$ & $40 \%$ & 3.3 & 6.3 \\
\hline Rimmon Heights & $\mathrm{R}$ & $29 \%$ & $\$ 63,000$ & 51 & $52 \%$ & $48 \%$ & 3.9 & 5.4 \\
\hline Wellington & $\mathrm{T}$ & $45 \%$ & $\$ 130,000$ & 53 & $44 \%$ & $58 \%$ & 0.2 & 1.1 \\
\hline Downtown Manch & $\mathrm{X}$ & $41 \%$ & $\$ 95,000$ & 53 & $67 \%$ & $38 \%$ & 5.9 & 7.6 \\
\hline Elmwood & Y & $10 \%$ & $\$ 14,000$ & 44 & $80 \%$ & $70 \%$ & 2.7 & 4.1 \\
\hline
\end{tabular}


Table 2. Cont.

\begin{tabular}{|c|c|c|c|c|c|c|c|c|}
\hline $\begin{array}{c}\text { Neighborhood } \\
\text { Name }\end{array}$ & Code & $\begin{array}{c}\text { \% Response } \\
\text { Rate }\end{array}$ & $\begin{array}{l}\text { Average } \\
\text { Income }\end{array}$ & Ave Age & $\begin{array}{c}\text { \% Residents Walk at } \\
\text { Least Once a Week }\end{array}$ & $\begin{array}{c}\text { \% Residents Listing } \\
\text { Sidewalk as Barrier * }\end{array}$ & $\begin{array}{c}\text { Ave Num Places } \\
\text { Do Walk } * *\end{array}$ & $\begin{array}{c}\text { Ave Num Places } \\
\text { Can Walk } \\
\end{array}$ \\
\hline Ports. Average & - & $37 \%$ & $\$ 85,000$ & 51 & $54 \%$ & $52 \%$ & 4.0 & 6.9 \\
\hline Atlantic Heights & A & $25 \%$ & $\$ 74,000$ & 43 & $36 \%$ & $64 \%$ & 2.5 & 5.7 \\
\hline Christian Shore & $\mathrm{C}$ & $35 \%$ & $\$ 76,000$ & 53 & $44 \%$ & $56 \%$ & 4.5 & 8.5 \\
\hline Downtown Ports & $\mathrm{D}$ & $46 \%$ & $\$ 90,000$ & 42 & $64 \%$ & $64 \%$ & 7.3 & 9.4 \\
\hline Elwyn Park & E & $32 \%$ & $\$ 74,000$ & 63 & $60 \%$ & $50 \%$ & 2.1 & 5.3 \\
\hline Frank Jones & $\mathrm{F}$ & $38 \%$ & $\$ 85,000$ & 54 & $43 \%$ & $63 \%$ & 1.9 & 7.4 \\
\hline Islington & I & $34 \%$ & $\$ 83,000$ & 43 & $58 \%$ & $36 \%$ & 6.5 & 9.5 \\
\hline Richards Ave & K & $65 \%$ & $\$ 118,000$ & 44 & $38 \%$ & $31 \%$ & 7.4 & 10.7 \\
\hline South Side & $\mathrm{S}$ & $52 \%$ & $\$ 92,000$ & 57 & $54 \%$ & $46 \%$ & 6.8 & 8.5 \\
\hline Sherbourne & V & $45 \%$ & $\$ 68,000$ & 53 & $49 \%$ & $62 \%$ & 1.5 & 1.4 \\
\hline Woodlands & $\mathrm{W}$ & $39 \%$ & $\$ 139,000$ & 53 & $74 \%$ & $54 \%$ & 1.7 & 5.6 \\
\hline Ledgewood & $\mathrm{Z}$ & $21 \%$ & $\$ 33,000$ & 41 & $67 \%$ & $19 \%$ & 2.3 & 6.4 \\
\hline
\end{tabular}

Note: * In answer to "What affects your decision to walk to different locations within your community? Check all that are applicable reasons", what percentage of survey respondents checked "Presence of Sidewalk"? ** Both the "do" walk and the "can" walk destinations are the number self-reported by survey respondents. 


\subsection{Data Sources}

Information about demographics and personal transportation behavior was collected from residents in the form of a survey: Mailed-back in paper form and available on-line [55]. Members of the research team delivered a paper-copy form with an envelope and an internet address for the online version to one hundred homes selected at random from within each of the predetermined neighborhood boundaries in the cities. Residents receiving the survey had the choice to complete the paper version and return in a stamped envelope, to complete the survey online, or to ignore the survey. A follow-up "reminder card" was sent to residents who did not return the survey during the first round.

The overall survey was based on the Saguaro Seminar's social capital short form, a shorter version of their 2000 Social Capital Community Benchmark (SCCB) survey that is available on the Saguaro Seminar's website. Added to the core SCCB survey were questions related to transportation (based upon Leyden [56]) and health (based upon the Behavioral Risk Factor Surveillance System (BRFSS) [57]). The specific transportation behavior questions used in this present analysis are presented in Table 3.

Table 3. Transportation behavior questions (from survey).

\begin{tabular}{|c|c|c|}
\hline NO. & & Questions \\
\hline 1 & \multicolumn{2}{|c|}{ On a scale from 1 to 5 , how convenient is it for you to walk in the neighborhood in which you live? } \\
\hline \multirow{8}{*}{$2 \mathrm{a}$} & \multicolumn{2}{|c|}{ Please indicate all of the locations that you can walk to in your community: } \\
\hline & Post office & Home of a friend \\
\hline & Restaurant & Grocery Store \\
\hline & Coffee Shop/Cafe & $\mathrm{Bar} / \mathrm{Pub}$ \\
\hline & Shopping center & Community/Recreation Center \\
\hline & Church & Convenience Store \\
\hline & School & Natural Area/Open Space/Park \\
\hline & Library/Bookstore & Other, please specify \\
\hline $2 \mathrm{~b}$ & \multicolumn{2}{|c|}{ Please indicate all of the locations that you do walk to in your community (same list as above). } \\
\hline 3 & \multicolumn{2}{|c|}{$\begin{array}{l}\text { Assume you were going to walk to one of the locations listed on the previous page. What would you consider a } \\
\text { maximum acceptable distance in minutes? }\end{array}$} \\
\hline 4 & \multicolumn{2}{|c|}{$\begin{array}{l}\text { What affects your decision to walk, bike, or drive to different locations within your community: weather, safety } \\
\text { concerns, gas prices, health issues, presence of sidewalk, distance to destination, } \\
\text { convenience of driving, inconvenience of walking, other? Indicate all that are applicable. }\end{array}$} \\
\hline
\end{tabular}

Metrics related to the physical form of the neighborhoods were calculated from Geographical Information Systems (GIS) data available from the two cities and from New Hampshire's statewide GIS database, GRANIT [58]. Built environment data were also collected and confirmed through field visits and through the use of online mapping services, such as Google Earth Street View.

\subsection{Variables}

\subsubsection{Outcome Variable: Number of Walking Destinations}

The outcome variable used to determine the personal transportation decisions made by residents was calculated from question $2 \mathrm{~b}$ in Table 3 , "Please indicate all of the locations that you do walk in your 
community." The number of places checked by residents was summed, excluding the "other" category, resulting in a metric that varied from 0 to 13.

\subsubsection{Explanatory Variables}

Demographic and individual perception variables (Table 4) derived from the survey of residents were first level (individual or resident level) variables. Built environment variables (Table 5), determined from GIS and field visits, were at the second (neighborhood) level. These variables were selected as they were expected to best characterize the neighborhoods and delineate the differences. As the study neighborhoods were all smaller than a census block, variables such as urban or population density [59] were not available for use; this is likely to be the case for many smaller cities and suburban/rural areas. Other variables, such as aesthetics [60] and scale [61] have been determined to influence walkability in other areas, however those variables did not appear to be important here. Additionally, scale does not vary a great deal between the neighborhoods within smaller cities.

Table 4. Explanatory variables: demographics and individual perceptions (from Survey).

\begin{tabular}{|c|c|c|}
\hline Variable & Survey Phrasing & Pre-Analysis Data Manipulation \\
\hline Age & "What year were you born?" & Center about the average age in 2009. \\
\hline $\begin{array}{l}\text { Self-Reported } \\
\text { Health }\end{array}$ & $\begin{array}{l}\text { "Describe your overall state } \\
\text { of health these days." }\end{array}$ & $\begin{array}{l}\text { Poor }=1, \text { Fair }=2, \text { Good }=3, \\
\text { Very Good }=4, \text { Excellent }=5\end{array}$ \\
\hline Income & $\begin{array}{l}\text { What is the total of yearly incomes, before taxes, of all } \\
\text { members of your household for the last year? } \\
\text { (Ten categories given) }\end{array}$ & $\begin{array}{l}\text { Assigned respondent midpoint of their } \\
\text { range. Respondents in the " } \$ 200,000 \text { or } \\
\text { more" category were assigned } \$ 200,000 \text {. }\end{array}$ \\
\hline Education & $\begin{array}{l}\text { "What is the highest grade of school or year of college } \\
\text { you have completed?" List modified from US Census } \\
\text { [25]. Less than H.S. = } 1 \text { High School diploma/GED = } 2\end{array}$ & $\begin{array}{l}\text { Some College }=3 \\
\text { Associate }(2 \text { year }) \text { or tech training }=4 \\
\text { Bachelor's degree }=5 \\
\text { Some graduate training }=6 \\
\text { Graduate or professional degree }=7\end{array}$ \\
\hline Gender & "What is your gender?" (Circle one) & Female $=1$, Male $=2$, Transgender $=$ N/A \\
\hline Race & $\begin{array}{l}\text { "What is your race? (Circle as many as } \\
\text { necessary)" List from U.S. Census } 2010 \text { [25]. }\end{array}$ & $\begin{array}{l}\text { Respondent circled only "white" }=1 \\
\text { Any other combination }=2 *\end{array}$ \\
\hline
\end{tabular}

Note: * Although there are other ways to present race [62], this method has been used by others in similar work [63].

Table 5. Explanatory variables: built environment.

\begin{tabular}{cl}
\hline Variable & Description \\
\hline $\begin{array}{c}\text { \& \& up-Legged } \\
\text { Intersections }\end{array}$ & Number intersections with three or more legs within a given neighborhood, divided by area. \\
\hline $\begin{array}{c}\text { \& up-Legged } \\
\text { Intersections }\end{array}$ & Number intersections with four or more legs within a given neighborhood, divided by area. \\
\hline Businesses & Number services listed in question 2a (Table 2) falling within bounds of each neighborhood. \\
\hline & $\begin{array}{l}\text { Presence and condition of sidewalks as percentage. 100\% = all streets have mint condition } \\
\text { sidewalks. 50\% = half of streets have mint sidewalks or all streets have sidewalks with poor } \\
\text { functionality. }\end{array}$ \\
\hline Lane Miles & Road miles in neighborhood divided by acres in neighborhood, excluding highways. \\
\hline
\end{tabular}




\section{Results}

\subsection{Data Summary}

\subsubsection{Survey Responses and Response Rates}

Surveys were distributed to a total of 2004 homes (Manchester: 1019; Portsmouth: 985). Of those, 715 survey responses were returned, inclusive of all paper and internet responses. Thirty six surveys were returned blank or with all indication of neighborhood or city removed. Therefore, a total of 679 surveys were usable, completed with location of residence known (Manchester: 319; Portsmouth: 360). The overall net response rate was 33.9\% (Manchester: 31.3\%; Portsmouth: 36.5\%).

In a meta-analysis of surveys to investigate impacts on response rate, Cook et al. [64] reported a mean response rate of $39.6 \%$ (standard deviation $=19.6 \%$ ) for 68 published internet surveys, and $34.6 \%$ (std. dev. $=15.7 \%$ ) for a subset of those surveys with more complete data. Fox et al. [65] reported a mean response rate of $40.0 \%$ (std. dev. $=17.1 \%$ ) for surveys without extensive follow up. The response rate for the present study was within one standard deviation of these reported mail and internet survey response rates.

\subsubsection{Survey Data-Socio-Demographics and Transportation Behavior}

More important than a high response rate is whether the responders were representative of the population to which inferences might be extended. Descriptive statistics for socio-demographic and transportation behavior characteristics are given in Table 2. The average age of survey respondents, 51 to 52 years, was slightly higher than the average from the US census (Manchester 45.0 years old, Portsmouth 46.3 years old, removing people younger than 20 years old) [25]. Age was included as an explanatory variable to investigate how age is related to the outcome.

The average respondent income was slightly higher than the census average, although the mean income category for the survey respondents included the census mean [25]. Although income was not significantly different from the city averages, it was included as an explanatory variable. Other basic demographics for survey respondents are included in Table 1 for comparison with US Census data [25].

\subsubsection{Importance of Clustering}

The intra-class correlation (ICC) is a measure of the increase in correlation of the outcome variable between individuals within a group over randomly selected individuals, and is calculated by dividing the group-level variance by the total variance [66]. "Neighborhood of residence" was used as the group; $u_{o j}$ was the random, or as yet undetermined, influences of neighborhood level variables; $e_{i j}$ was the random, or as yet undetermined, influences of individual level variables. Using Stata to fit the data to this model, the variance in the neighborhood-level random effects, $u_{o j}$, was $\sigma_{u}^{2}=4.46$, while the variance for individual level variables, $e_{i j}$, was $\sigma_{\mathrm{e}}^{2}=7.42$. The ICC is $\sigma_{\mathrm{u}}^{2} /\left(\sigma_{\mathrm{e}}^{2}+\sigma_{\mathrm{u}}^{2}\right)=38 \%$. Therefore, $38 \%$ of the total variation in the data could be attributed to neighborhood effects.

A second measure of the importance of clustering in the data is the design effect [12]. The design effect is the ratio of actual variance (given that our sampling method was not entirely random, but rather involved randomly selecting households from within pre-determined neighborhood clusters) to the variance 
if we assume simple random sampling with no clustering. The design effect calculated was a relatively high 11.9, indicating that the neighborhood was an important level of analysis for this data.

Both the ICC and the design effect of the present study point to the importance of neighborhood-level data in analyzing walkability. To most effectively accomplish this quantitatively, we used multilevel modeling, or "cluster" modeling [67,68]. Individual survey respondents were nested within their neighborhoods in a hierarchical structure [66].

\subsection{Data Analysis}

Of the demographic variables, only age was consistently significant when other variables were included in the analysis. Health, income, and education were not significant in the presence of age. The maximum acceptable distance in minutes that residents were willing to walk ("maxtime" from Table 3) also remained significant when other explanatory variables were included.

Of the built environment variables, sidewalks and intersections ( 3 or more legs) were significantly associated with the number of places residents reported that they do walk, even while other variables were included. Surprisingly, in the presence of other variables, the number of local destinations was not significantly related to the number of places residents walk. Similarly, the variable "road lane miles" was not significant when other variables were included in the model.

Adding the significant explanatory variables: Age, maximum acceptable distance in minutes that residents were willing to walk ("maxtime"), intersections and sidewalks, the model became:

$$
\begin{gathered}
\text { Sumdo }_{\mathrm{ij}}=-0.159+(-0.038) \times \text { age }+3.72 \times \text { sidewalks }+0.047 \times \text { maxtime } \\
+3.20 \times \text { inters }+u_{o j}+e_{i j}
\end{gathered}
$$

where: Sumdo = outcome variable, number of locations to which residents walk (question 2b, Table 3); Age $=$ centered age $(z=-5.21, p<0.01$, Confidence Interval: CI $(-0.052$ to -0.023$))$; Sidewalks $=$ proportion of sidewalks in neighborhood $(z=4.24, p<0.01$, CI (2.00 to 5.43)); Maxtime = resident's self-declared max time of walking $(z=4.39, p<0.01, \mathrm{CI}(0.026$ to 0.068$))$; Inters $=$ count of intersections (three-leg or more) neighborhood $(z=3.67, p<0.01$, CI $(1.49$ to 4.91$))$; Constant $=(z=0.37, p=0.715$, CI (-1.01 to 0.69$))$.

The remaining resident level variance, $\sigma_{\mathrm{e}}{ }^{2}$, was 6.58 . The neighborhood level variance, $\sigma_{\mathrm{u}}{ }^{2}$, dropped from 4.45 for the basic model with no explanatory variables to 0.60 with the above explanatory variables included. The variables thus explained a great deal of variance between neighborhoods, but did not explain as much of the variance between individuals.

\section{Discussion and Conclusions}

\subsection{Model_Explanatory Variables: Demographics and Individual Perceptions}

The variables based directly on survey data were first-level variables, associated with individual residents, while second-level variables (sidewalks, intersections) were ecological variables associated with neighborhoods. First-level variables therefore helped describe the variance between individual behavior, but not between neighborhoods. When averaged over all respondents within a neighborhood, however, a first-level variable became a second-level variable (such as average age in a neighborhood). 
Age-Respondents were asked their year of birth, and age was calculated from that response. Walking is an important component of an active and healthy lifestyle at all stages of life, but particularly for the elderly [69]. However, as we age, walking for transportation may become less feasible. Age was therefore expected to be negatively associated with the outcome variable, and our results confirmed this. As residents get older they walk less. However, while the relationship was significant, the coefficient, or slope, was quite low (-0.04). Both the sidewalks and intersections had much higher coefficients, indicating that a built environment that is conducive to walking may allow older adults to be more physically active. The average age of each neighborhood (second level variable) was not significantly related to the variability in destination walking between neighborhoods.

Self-reported health - Survey respondents were asked to rank their own health on a Likert scale from poor to excellent [12]. One's physical health, as well as the perception of one's own health, may impact physical activity as those in very poor health may be unable to engage in utilitarian walking behaviors. Although this variable was significant alone, it became less so in the presence of age, indicating perhaps that the variable age better accounted for reduction in the respondents destination walking due to reduced health. Self-reported health lost significance entirely when both age and sidewalks were included in the model.

Income and Education - Both income and education have been observed to be moderately correlated with walking [70], although other work indicated that socioeconomic status does not impact walking prevalence [71]. Either way, these variables may influence the outcome variable; residents who cannot afford a car may be forced to walk (rather than choosing to walk) as a primary form of transportation, and thus may also have other economic impacts such as reduced access to medical care or food [72]. Income and education, therefore, may be interaction variables, potentially changing the way other variables are correlated to the outcome. Our results, however, did not bear this out. Although both education and income were significant if they are the only variable, they each lost significance entirely when age was introduced to the model, potentially indicating that real differences between neighborhoods were lost in the larger scale, multi-neighborhood analysis. For example, although there were some lower income residents who, in the comments, indicated they did not own a car, this did not seem to be a statistically significant condition for the survey respondents.

Gender and Race-Neither was significantly correlated with destination walking, either alone or in the presence of other variables.

Maxtime-The third question in Table 3, "what would you consider a maximum acceptable distance in minutes", was a measure of personal perception of the acceptability of walking as a means of transportation. This measure represented a particular resident's preference for walking and may, therefore, have been a proxy for neighborhood self-selection [73]. Maxtime was significantly correlated with number of walking destinations, both alone and with other variables. As with age, however, it did not explain any of the between-neighborhood variation, either as an individual level variable, or when averaged across the neighborhood to form a neighborhood-level variable. The maximum time that respondents were willing to walk was not significantly correlated with built environment metrics, such as sidewalks, connectivity, or road lane miles.

The time that residents are willing to walk was positively correlated with walking; residents who were willing to walk for longer periods of time were more likely to walk in their neighborhood. Although this is a rather obvious outcome, it raised the issue of whether it is possible to increase the time or distance 
that residents are willing to walk. If walking was made to appear more socially acceptable, safer, or more convenient, would residents walk more often and therefore gain health benefits? If changes are made to the built environment in the neighborhoods studied, a follow up study may help determine what cultural or social changes support greater use of new infrastructure [74].

\subsection{Model—Explanatory Variables: Built Environment}

Intersections-Density of intersections (number divided by area) characterized the connectivity of the local street network. Although connectivity has been surmised to be positively correlated with walking [75,76], perceived safety of intersections may also impact destination walking [12]. The number of intersections, calculated for each neighborhood, was a second-level variable.

As Frank et al. [77] suggested, intersections were correlated with walking for transportation; neighborhoods with more connections were walked more often than those with fewer connections. However, interestingly, intersections with four or more legs were not correlated with walking, while intersections with three or more legs were. More investigation is necessary to determine why this is, for example if perceived safety is a factor, if specific intersections are skewing the results, or if simply three-legged intersections are what are present, and these intersections improve connectivity, if not as well as additional four-legged intersections might.

Businesses-Previous studies have shown mixed results as to the importance of nearby businesses [78,79]. This second level variable counted the number of services listed in question $2 \mathrm{a}$ (Table 3) that fell within the bounds of each neighborhood (e.g., five restaurants + two parks + three churches $=10$ destinations). Although significantly correlated to destination walking when it was the only explanatory variable, the count of nearby destinations was not significantly correlated when the "sidewalks" variable was added to the model.

Lane Miles - "Road lane miles per acre" is a measure of road density often used as a measure of the built environment [80]. This second level variable was calculated as the road miles in the neighborhood, excluding highways, divided by the total number of acres in the neighborhood. This variable was significantly correlated when it was the only explanatory variable or in the presence of the variable "sidewalks", but was not significantly correlated when the three-and-up-legged-intersections variable was included in the model.

Sidewalks - Presence and condition of sidewalks was estimated as a percentage for each neighborhood, with $100 \%$ meaning all streets in the neighborhood have "mint" condition sidewalks, and $25 \%$ signifying a neighborhood with poor quality sidewalks on only half of its streets $(0.5 \times 0.5)$. Based on the neighborhood, this was a second level variable.

Sidewalks were strongly positively correlated with walking [76]; residents generally seem to walk more where suitable sidewalks available. Sidewalks may also have been a proxy for other unmeasured characteristics, such as a local culture of walking, street trees, etc. However, it would appear that in many neighborhoods, discussion about availability of sidewalks or walking paths is a place to start for a municipality that wants to encourage healthful physical activity and reduce automotive traffic.

Residual Variables - In addition to the measured variables, described above, two variables intended to describe residual effects are included in the model, $u_{o j}$ and $e_{i j}$. The $u_{o j}$ represents the deviation of an individual's $(j)$ mean from the overall average expected mean, while $e_{i j}$ represents the deviation of 
a particular observation (i) from an individual's $(j)$ mean [81]. Together the residual variables describe why a particular model outcome might not occur exactly as predicted.

\subsection{Focus Groups-Qualitative Data}

Discussions with municipal employees revealed more specific results about the study areas. Certain neighborhoods reportedly have individual characteristics related to walkability. For example, one neighborhood has actively lobbied against having sidewalks installed out of fear of an increase in people from outside the neighborhood passing through. Understanding and managing these perceptions, while providing improved infrastructure, can be extremely challenging. Both cities were conducting long-term analyses of pedestrian safety, and actively sought to improve local amenities, but what "improve" means may vary sharply between neighborhoods.

\subsection{Practical Implications}

While modeling provided some interesting findings across the neighborhoods, results also suggest each neighborhood is unique in which structural retrofits might make the greatest impact. In neighborhood Y, which had the lowest average income, $70 \%$ of survey respondents selected "presence of sidewalks" as a response to the question "What affects your decision to walk to different locations within your community?" (Table 2). Respondents reported that they walk to an average of 2.7 destinations. The neighborhood received a sidewalk score of 0.5 . If sidewalk access were improved, raising the sidewalk score to 0.75 , the model suggested that the average number of places residents might walk could increase by a factor of 3.72 , or $(0.75 \times 3.72)=2.79$, almost three additional destinations. However, there remains a great deal of unaccounted for variability in the modeled relationships, other local factors may result in more or less impact from sidewalk improvement.

Emerging research methods such as Participatory Geographic Information Systems (PGIS) [82,83] may improve our understanding of residents" "place attachment" and connections to their neighborhood [84], thereby complementing quantitative models.

\subsection{Conclusions}

When modeling on an average-by-neighborhood basis, built environment metrics "sidewalks" and "intersections" were strongly correlated with the reported number of walking destinations. However, on a smaller scale, between individual neighborhoods, other drivers emerged. Individual needs of neighborhoods, and not simply one-size-fits-all solutions, seemed to influence residents' perception of walkability and walking behaviors.

Overall, municipalities may wish to follow a similar methodology: Identify neighborhoods which might benefit from reduced barriers to walking (i.e., low income, center city), identify potential barriers to walking (i.e., lack or disrepair of sidewalks), engage residents in participatory processes to better understand their perceptions and contextual variations, and prioritize specific improvements [54]. 


\section{Study Limitations and Future Directions}

This present study only included neighborhoods in two small cities, which was not sufficient to investigate neighborhood- and city-level differences with sufficient statistical power or to compare the results to outcomes from larger cities. Expansion to other small cities would enable researchers to examine the impact that city-wide planning efforts, culture, bus systems, etc. might have on personal transportation decisions of residents. It may also be instructive to compare results between neighborhoods within larger metropolitan areas and neighborhoods in isolated small cities.

There remains a great deal of unexplained variation in the individual level data. Residents, even in very walkable neighborhoods, may choose not to walk. To explore how tightly residents hold preferences, individual-level variables [85-87], such as social support, residential preferences, perceptions of safety, and personal health, which were included in the survey discussed here, could be investigated through collaborative engagement processes (such as Health Impact Assessment, HIA) [88]. Further, coupling community engagement with newer forms of systems-science modeling, such as Agent Based Modeling, could allow for more individualistic investigation of survey subjects, may be a good fit for this type of data. Triangulating quantitative, qualitative, and systems science methods may help to better understand walking behavior in future research. Individual-level correlates of behavior have been Outreach programs have been shown to be effective in increasing physical activity in older adults [74]. Oakes [62] suggested randomizing interventions to neighborhoods as a way to investigate causality, or utilizing techniques such as propensity score matching or instrumental variables to minimize the limitations of observational studies.

To more fully investigate the ways that improved walkability can support sustainability and reduce overall vehicle trips and vehicle miles, additional variables such as number of walking trips could be added. Additionally, while this study focused on adult walking behavior, it may be of interest to explore links between these findings and other studies on child walking behavior [89].

\section{Acknowledgments}

The authors owe gratitude to those who helped make this study a reality: Joanne Theriault and Sarah Kissell for assistance distributing the survey, Remy Dumas for assistance in estimating the sidewalk conditions, and Ben Brown for assistance distributing the survey, entering data, and performing analyses. We would also like to thank the Cities of Manchester and Portsmouth, New Hampshire for providing guidance and support throughout the project. Funding for this research was provided by the University of New Hampshire through a Sustainability Fellow Grant, UNH's Environmental Research Group, and the U.S. EPA. The research described in this paper has been funded in part by the United States Environmental Protection Agency (EPA) under the Science to Achieve Results (STAR) Graduate Fellowship Program. EPA has not officially endorsed this publication and the views expressed herein may not reflect the views of the EPA. The authors are also grateful to the three anonymous reviewers who provided thoughtful feedback and guidance. 


\section{Author Contributions}

Kevin Gardner conceived the study, and designed the work along with Cynthia Carlson and Shannon Rogers. Cynthia Carlson and Shannon Rogers performed the experiments and analyzed the data. Semra Aytur contributed analysis support. Cynthia Carlson wrote the paper with support of the other listed authors.

\section{Conflicts of Interest}

The authors declare no conflict of interest.

\section{References}

1. National Research Council (US). Does the Built Environment Influence Physical Activity: Examining the Evidence; Transportation Research Board: Washington, DC, USA, 2005.

2. Jackson, R.J. The impact of the built environment on health: An emerging field. Am. J. Public Health 2003, 93, 1382-1384.

3. Berrigan, D.; McKinnon, R.A. Built environment and health. Prev. Med. 2008, 47, 239-240.

4. Frank, L.D.; Engelke, P.O. The built environment and human activity patterns: Exploring the impacts of urban form on public health. J. Plan. Lit. 2001, 16, 202-218.

5. Handy, S.L.; Boarnet, M.G.; Ewing, R.; Killingsworth, R.E. How the built environment affects physical activity. Am. J. Prev. Med. 2002, 23, 64-73.

6. Ewing, R.; Bartholomew, K.; Winkelman, S.; Walters, J.; Chen, D. Growing Cooler: The Evidence on Urban Development and Climate Change; Urban Land Institute: Washington, DC, USA, 2007.

7. Bagley, M.N.; Mokhtarian, P.L. The impact of residential neighborhood type on travel behavior: A structural equations modeling approach. Ann. Reg. Sci. 2002, 36, 279-297.

8. Ewing, R.; Cervero, R. Travel and the built environment: A synthesis. Transp. Res. Rec. 2001, 1780, 87-114.

9. Owen, N.; Humpel, N.; Leslie, E.; Bauman, A.; Sallis, J.F. Understanding environmental influences on walking. Am. J. Prev. Med. 2004, 27, 67-76.

10. Naess, P. Accessibility, activity participation and location of activities: Exploring the links between residential location and travel behaviour. Urban Stud. 2006, 43, 627-652.

11. Hoehner, C.M.; Brennan Ramirez, L.K.; Elliott, M.B.; Handy, S.L.; Brownson, R.C. Perceived and objective environmental measures and physical activity among urban adults. Am. J. Prev. Med. 2005, 28, 105-116.

12. Li, F. Multilevel modelling of built environment characteristics related to neighbourhood walking activity in older adults. J. Epidemiol. Community Health 2005, 59, 558-564.

13. Shay, E.; Rodriguez, D.A.; Cho, G.; Clifton, K.J.; Evenson, K.R. Comparing objective measures of environmental supports for pedestrian travel in adults. Int. J. Health Geogr. 2009, 8, doi:10.1186/ 1476-072X-8-62.

14. Carlson, C.; Aytur, S.; Gardner, K.; Rogers, S. Complexity in built environment, health, and destination walking: A neighborhood-scale analysis. J. Urban Health 2012, 89, 270-284. 
15. Howard, E.J.; Kang, B.; Hurvitz, P.; Moudon, A.V.; Saelens, B.E. Modeling GPS-Based Walking Activity and Its Association with Objectively Measured Built Environment. In Proceedings of the Transportation Research Board 93rd Annual Meeting, Washington, DC, USA, 12-16 January 2014.

16. Vance, C.; Hedel, R. The impact of urban form on automobile travel: Disentangling causation from correlation. Transportation 2007, 34, 575-588.

17. Charreire, H.; Weber, C.; Chaix, B.; Salze, P.; Casey, R.; Banos, A.; Badariotti, D.; Kesse-Guyot, E.; Hercberg, S.; Simon, C.; et al. Identifying built environmental patterns using cluster analysis and GIS: Relationships with walking, cycling and body mass index in French adults. Int. J. Behav. Nutr. Phys. Act. 2012, 9, doi:10.1186/1479-5868-9-59.

18. Bell, D.; Jayne, M. Small cities? Towards a research agenda. Int. J. Urban Reg. Res. 2009, 33, 683-699.

19. Macera, C.A.; Ham, S.A.; Yore, M.M.; Jones, D.A.; Ainsworth, B.E.; Kimsey, C.D.; Kohl, H.W., 3rd. Prevalence of physical activity in the united states: Behavioral risk factor surveillance system, 2001. Prev. Chronic Dis. 2005, 2, 1-10.

20. Control, C.F.D. Healthy Weight_-It's Not A Diet, It's A Lifestyle! Available online: http://www. cdc.gov/obesity/adult/defining.html (accessed on 29 June 2015).

21. Cox, J.W. Mini-D.C.'S.: A Small-City Boom Revitalizes Downtowns Once Left for Dead. The Washington Post. Available online: https://www.washingtonpost.com/local/mini-dcs-a-smallcity-boom-revitalizes-downtowns-once-left-for-dead/2014/10/31/0790173e-5f9b-11e4-91f7-5d89 b5e8c251_story.html (accessed on 21 October 2015).

22. Van Heur, B. Small cities and the sociospatial specificity of economic development. In Cultural Political Economy of Small Cities; Lorentzen, A., van Heur, B., Eds.; Routledge: London, UK, 2012.

23. Vias, A. Micropolitan areas and urbanization processes in the US. Cities 2011, 29, S24-S28.

24. Willits, D.; Nowacki, J. Police organisation and deadly force: An examination of variation across large and small cities. Polic. Soc. 2014, 24, 63-80.

25. U.S. Census Bureau. Demographic Profiles. Available online: http://censtats.census.gov/pub/ Profiles.shtml (accessed on 10 June 2015).

26. Victoria Transport Policy Institute. New Urbanism: Clustered, Mixed Use, Multi-Modal Neighborhood Design. Available online: http://www.vtpi.org/tdm/tdm24.htm (accessed on 10 June 2015).

27. U.S. Green Building Council. Leed Reference Guide for Green Neighborhood Development; U.S. Green Building Council: Washington, DC, USA, 2009.

28. Christian, H.; Knuiman, M.; Bull, F.; Timperio, A.; Foster, S.; Divitini, M.; Middleton, N.; Giles-Corti, B. A new urban planning code's impact on walking: The residential environments project. Am. J. Public Health 2013, 103, 1219-1228.

29. Whitford, J. Definition of Sustainable Planning Principles—Community Energy Plan Action Area 6; City of Yellowknife Community Energy Planning Committee: Yellowknife, NT, Canada, 2006.

30. Rodríguez, D.A.; Aytur, S.; Forsyth, A.; Oakes, J.M.; Clifton, K.J. Relation of modifiable neighborhood attributes to walking. Prev. Med. 2008, 47, 260-264.

31. MacGillis, A. Funding Rules Fuel Clash within Mass Transit World. The Washington Post. Available online: http://www.washingtonpost.com/wp-dyn/content/article/2010/06/10/ AR2010061005535.html (accessed on 21 October 2015).

32. Gerdtham, U.G. Equity in health care utilization: Further tests based on hurdle models and Swedish micro data. Health Econ. 1997, 6, 303-319. 
33. University, K.S. Low-Income Women Living in Small Cities Have Higher Chance of Obesity, Study Finds. ScienceDaily. Available online: http:/www.sciencedaily.com/releases/2010/03/ 100309111641.htm (accessed on 21 October 2015).

34. Kemperman, A.; Timmerman, H. Influences of built environment on walking and cycling by latent segments of aging population. Transp. Res. Rec. J. Transp. Res. Board 2009, 2134, 1-9.

35. Cheng, J.J.; Berry, P. Health co-benefits and risks of public health adaptation strategies to climate change: A review of current literature. Int. J. Public Health 2012, 58, 305-311.

36. Younger, M.; Morrow-Almeida, H.R.; Vindigni, S.M.; Dannenberg, A.L. The built environment, climate change, and health. Am. J. Prev. Med. 2008, 35, 517-526.

37. Pitkin, J.M.D. U.S. Housing Trends: Generational Changes and the Outlook to 2050. Available online: http://onlinepubs.trb.org/Onlinepubs/sr/sr298pitkin-myers.pdf (accessed on 19 October 2015).

38. Van Dyck, D.; Cardon, G.; Deforche, B.; Owen, N.; de Bourdeaudhuij, I. Relationships between neighborhood walkability and adults' physical activity: How important is residential self-selection? Health Place 2011, 17, 1011-1014.

39. Cao, X. Examining the impacts of neighborhood design and residential self-selection on active travel: A methodological assessment. Urban Geogr. 2015, 36, 236-255.

40. Southworth, M.; Owens, P.M. The evolving metropolis: Studies of community, neighborhood, and street form at the urban edge. J. Am. Plan. Assoc. 1993, 59, 271-287.

41. Ewing, R.; Pendall, R.; Chen, D. Measuring sprawl and its transportation impacts. Transp. Res. Rec. 2003, 1831, 175-183.

42. Krieger, N. Geocoding and monitoring of us socioeconomic inequalities in mortality and cancer incidence: Does the choice of area-based measure and geographic level matter?: The public health disparities geocoding project. Am. J. Epidemiol. 2002, 156, 471-482.

43. Adkins, A.; Dill, J.; Luhr, G.; Neal, M. Unpacking walkability: Testing the influence of urban design features on perceptions of walking environment attractiveness. J. Urban Des. 2012, 17, 499-510.

44. Anderson, E. Code of the Street: Decency, Violence, and the Moral Life of the Inner City; WW Norton \& Company: New York, NY, USA, 2000.

45. Krizek, K.J. Residential relocation and changes in urban travel: Does neighborhood-scale urban form matter? J. Am. Plan. Assoc. 2003, 69, 265-281.

46. Cerin, E.; Lee, K.Y.; Barnett, A.; Sit, C.H.P.; Cheung, M.C.; Chan, W.M.; Johnston, J.M. Walking for transportation in hong kong chinese urban elders: A cross-sectional study on what destinations matter and when. Int. J. Behav. Nutr. Phys. Act. 2013, 10, doi:10.1186/1479-5868-10-78.

47. Paul, P.; Carlson, S.A.; Carroll, D.D.; Berrigan, D.; Fulton, J.E. Walking for transportation and leisure among U.S. Adults - National health interview survey 2010. JPAH 2014, 12, S62-S69.

48. Leung, M.W. Community based participatory research: A promising approach for increasing epidemiology's relevance in the 21st century. Int. J. Epidemiol. 2004, 33, 499-506.

49. Eco-Municipalities. Available online: http://www.instituteforecomunicipalities.org/Ecomunicipalities.html (accessed on 29 May 2015).

50. City of Portsmouth. Portsmouth Community Newsletter, 68th ed.; City of Portsmouth : Portsmouth, NH, USA, 2008.

51. James, S.L.T. The Natural Step for Communities: How Cities and Towns Can Change to Sustainable Practices; New Society Publishers: Gabriola Island, BC, Canada, 2004. 
52. Foreign Language Medical and Legal Interpretation. Available online: http:// www.snhahec.org/ flmi.cfm (accessed on 9 June 2015).

53. Believe in a Healthy Community: Greater Manchester Community Needs Assessment 2009. Available online: http:/www.manchesternh.gov/website/Departments/Health/DataandReports/ tabid/700/Default.aspx (accessed on 10 June 2015).

54. Young, J. A Community Schools Approach to Accessing Services and Improving Neighborhood Outcomes in Manchester, New Hampshire; University of New Hampshire: Durham, NH, USA, 2015.

55. Steele, J.; Bourke, L.; Luloff, A.E.; Liao, P.S.; Theodori, G.L.; Krannich, R.S. The drop-off/pick-up method for household survey research. Community Dev. Soc. J. 2001, 32, 238-250.

56. Leyden, K.M. Social capital and the built environment: The importance of walkable neighborhoods. Am. J. Public Health 2003, 93, 1546-1551.

57. Control, C.F.D. Brfss: Annual Survey Data. Available online: http://www.cdc.gov/brfss/annual data/annual_data.htm (accessed on 29 July 2015).

58. NH GRANIT. New Hampshire's Statewide GIS Clearinghouse. Available online: www.granit.unh.edu. (accessed on 19 October 2015).

59. Mindali, O.; Rayeh, A.; Salomon, I. Urban density and energy consumption: A new look at old statistics. Transp. Res. Part A Policy Pract. 2004, 38, 143-162.

60. Leslie, E.; Saelens, B.E.; Frank,D.; Owen, N.; Bauman, A.; Coffee, N.; Hugo, G. Residents' perceptions of walkability attributes in objectively different neighborhoods: A pilot study. Health Place 2005, 11, 227-236.

61. Ewing, R.; Handy, S.; Brownson, R.C.; Clemente, O.; Winston, E. Identifying and measuring urban design qualities related to walkability. J. Phys. Act. Health 2006, 3, S223-S240.

62. Oakes, J.M. The (mis)estimation of neighborhood effects: Causal inference for a practicable social epidemiology. Soc. Sci. Med. 2004, 58, 1929-1952.

63. Bhopal, R.; Donaldson, L. White, european, western, caucasian, or what? Inappropriate labeling in research on race, ethnicity, and health. Am. J. Public Health 1998, 88, 1303-1307.

64. Cook, C.; Heath, F.; Thompson, R.L. A meta-analysis of response rates in web- or internet-based surveys. Educ. Psychol. Meas. 2000, 60, 821-836.

65. Fox, R.J.; Crask, M.R.; Kim, J. Mail survey response rate: A meta-analysis of selected techniques for inducing response. Public Opin. Q. 1988, 52, 467-491.

66. Rasbash, J. Multilevel Modelling Course, Module 4: Multilevel Structures and Classifications; University of Bristol: Bristol, UK, 2008.

67. Snijders, T.A.B.R. Multilevel Analysis; Sage Publications: Thousand Oaks, CA, USA, 1999.

68. Steele, F. Multilevel Modelling Course, Module 5: Introduction to Multilevel Modelling Concepts; University of Bristol: Bristol, UK, 2008.

69. Berke, E.M.; Koepsell, T.D.; Moudon, A.V.; Hoskins, R.E.; Larson, E.B. Association of the built environment with physical activity and obesity in older persons. Am. J. Public Health 2007, 97, 486-492.

70. Hallal, P.C.; Azevedo, M.R.; Reichert, F.F.; Siqueira, F.V.; Araújo, C.L.P.; Victora, C.G. Who, when, and how much? Am. J. Prev. Med. 2005, 28, 156-161.

71. Siegel, P.Z.; Brackbill, R.M.; Heath, G.W. The epidemiology of walking for exercise: Implications for promoting activity among sedentary groups. Am. J. Public Health 1995, 85, 706-710. 
72. Bostock, L. Pathways of disadvantage? Walking as a mode of transport among low-income mothers. Health Soc. Care Community 2001, 9, 11-18.

73. Handy, S.; Cao, X.; Mokhtarian, P.L. Self-selection in the relationship between the built environment and walking: Empirical evidence from northern california. J. Am. Plan. Assoc. 2006, 72, 55-74.

74. Fisher, K.J.; Li, F. A community-based walking trial to improve neighborhood quality of life in older adults: A multilevel analysis. Ann. Behav. Med. 2004, 28, 186-194.

75. Saelens, B.E.; Sallis, J.F.; Frank, L.D.; Cain, K.L.; Conway, T.L.; Chapman, J.E.; Slymen, D.J.; Kerr, J. Neighborhood environment and psychosocial correlates of adults' physical activity. Med. Sci. Sports Exerc. 2012, 44, 637-646.

76. Saelens, B.E.; Sallis, J.F.; Frank, L.D. Environmental correlates of walking and cycling: Findings from the transportation, urban design, and planning literatures. Ann. Behav. Med. 2003, 25, 80-91.

77. Frank, L.D.; Andresen, M.A.; Schmid, T.L. Obesity relationships with community design, physical activity, and time spent in cars. Am. J. Prev. Med. 2004, 27, 87-96.

78. Handy, S.L.; Clifton, K.J. Local shopping as a strategy for reducing automobile travel. Transportation 2001, 28, 317-346.

79. McCormack, G.R.; Giles-Corti, B.; Bulsara, M. The relationship between destination proximity, destination mix and physical activity behaviors. Prev. Med. 2008, 46, 33-40.

80. Cervero, R.H.M. Induced travel demand and induced road investment: A simultaneous equation analysis. J. Transp. Econ. Policy 2002, 36, 469-490.

81. Rabe-Hesketh, S.; Skrondal, A. Multilevel and Longitudinal Modeling Using Stata; Stata Press: College Station, TX, USA, 2008.

82. Brown, G.; Fagerholm, N. Empirical PPGIS/PGIS mapping of ecosystem services: A review and evaluation. Ecosyst. Serv. 2015, 13, 119-133.

83. Brown, G.; Schebella, M.F.; Weber, D. Using participatory gis to measure physical activity and urban park benefits. Landsc. Urban Plan. 2014, 121, 34-44.

84. Brehm, J.M.; Eisenhauer, B.W.; Stedman, R.C. Environmental concern: Examining the role of place meaning and place attachment. Soc. Natl. Resour. 2013, 26, 522-538.

85. Giles-Corti, B.D.; Robert, J. Relative influences of individual, social environmental, and physical environmental correlates of walking. Am. J. Public Health 2003, 93, 1583-1589.

86. Larco, N.S.B.; Stockard, J.; West, A. Pedestrian-friendly environments and active travel for residents of multifamily housing the role of preferences and perceptions. Environ. Behav. 2012, 44, 303-333.

87. Ajzen, I. From intentions to action: A theory of planned behavior. In Action-Control: From Cognition to Behavior; Kuhl, J., Beckmann, J., Eds.; Springer: Heidelberg, Germany, 1985; pp. 11-39.

88. SNHPC. Second Street Corridor Health Impact Assessment; Southern New Hampshire Planning Commission: Manchester, NH, USA, 2013.

89. Kerr, J.; Frank, L.; Sallis, J.F.; Chapman, J. Urban form correlates of pedestrian travel in youth: Differences by gender, race-ethnicity and household attributes. Transp. Res. D Transp. Environ. 2007, $12,177-182$.

(C) 2015 by the authors; licensee MDPI, Basel, Switzerland. This article is an open access article distributed under the terms and conditions of the Creative Commons Attribution license (http://creativecommons.org/licenses/by/4.0/). 